EPJ Web of Conferences 45, 01127 (2013)

DOI: $10.1051 /$ epjconf/20134501127

(C) Owned by the authors, published by EDP Sciences, 2013

\title{
Experimental investigations of the performance of a solar air collector with latent heat thermal storage integrated with the solar absorber
}

\author{
P. Charvat ${ }^{1, \mathrm{a}}$, O. Pech ${ }^{1}$, and J. Hejcik ${ }^{1}$ \\ ${ }^{1}$ Brno University of Technology, Faculty of Mechanical Engineering, Technicka 2896/2, Brno, Czech Republic
}

\begin{abstract}
The paper deals with experimental investigations of the performance of a solar air collector with latent heat thermal storage integrated with the solar absorber. The main purpose of heat storage in solar thermal systems is to store heat when the supply of solar heat exceeds demand and release it when otherwise. A number of heat storage materials can be used for this purpose; the phase change materials among them. Short-term latent heat thermal storage integrated with the solar absorber can stabilize the air temperature at the outlet of the collector on cloudy days when solar radiation intensity incident on a solar collector fluctuates significantly. Two experimental front-and-back pass solar air collectors of the same dimensions have been built for the experimental investigations. One collector had a "conventional" solar absorber made of a metal sheet while the solar absorber of the other collector consisted of containers filled with organic phase change material. The experimental collectors were positioned side by side during the investigations to ensure the same operating conditions (incident solar radiation, outdoor temperature).
\end{abstract}

\section{Introduction}

The solar air collectors (or solar air heaters as they are sometimes called) are not as common as the solar collectors with liquid heat carriers. Nevertheless, the solar air collectors are rather simple and non-expensive devices [1] and they can be used for various purposes the most common being food or other product drying, space heating and ventilation air heating $[2,3]$. The solar air collectors/heaters can be of various designs. The collectors can either be glazed or unglazed. An unglazed solar air collector is generally an air channel behind a non-transparent surface that serves as a solar absorber. The absorber surface can be perforated and the outdoor air flows through the openings into the air cavity behind the absorber from which it is usually drawn into a ventilation or warm air heating system. Such transpired collectors [4] are usually used as façade elements and they can cover vast areas of otherwise unused façades of windowless buildings like assembly halls or warehouses.

The glazed solar air collectors offer even larger variation of possible designs. Similar to glazed solar collectors with liquid heat carriers the flat plate type of a collector is the most common. The shape of the solar absorber also plays a role in thermal performance of the collector [5]. As for glazing, a single pane glass is usually used for glazed solar air collectors but the double-glazing can also be used to reduce the transmission heat loss. The number of glazing panes influences the optical loss of the collector. An unglazed collector has generally a smaller optical loss than a collector with single pane glazing and the single pane glazing has smaller optical loss than double glazing. The optical loss and the transmission heat loss are two major energy losses of the solar air collectors. Contrary to the optical loss the transmission heat loss generally decreases with the number of glazing panes. An unglazed solar air collector has larger transmission heat loss than an air collector with singlepane glazing and the collector with double-pane glazing has generally smaller transmission heat loss than a collector with single-pane glazing. Other types of glazing such as translucent granular aerogel cover [6].

It is not possible to say that there is a best solar air collector design only the best design for a specific purpose. Finding the best collector design for a specific purpose (mainly operating conditions) is usually a matter of optimisation - balancing of optical and transmission losses as well as other design parameters.

Most solar thermal energy systems require heat storage in order cope with variation of supply and demand of heat. Depending on application heat storage can balance differences between supply and demand of heat in the time periods from minutes to months. Both sensible and latent heat storage materials can be used for thermal storage units in solar systems. More information about thermal energy storage used with solar air collectors can be found in [7].

This paper deals with experimental investigations of the performance of short-term heat storage integrated with solar absorber of a solar air collector.

\footnotetext{
acharvat@fme.vutbr.cz
} 


\section{Description of the case study}

The main goal of the experimental investigations reported in this paper was to assess the thermal performance of a solar air collector with latent heat storage integrated with the solar absorber. The investigations involved two flat plate, single-glazed, front-and-back pass experimental solar air collectors of the same dimensions. A front-andback pass solar air collector is a collector where air (heat carrier fluid) passes in the same direction on both sides of the solar absorber. This arrangement was chosen because it offers larger heat exchange area between the absorber and the passing air than the front-pass or the back-pass collector designs.

\subsection{Experimental solar air collectors}

The dimensions of the aperture of each of the two collectors were $900 \mathrm{~mm}$ by $1500 \mathrm{~mm}$. The air cavity on each side of the solar absorber was $25 \mathrm{~mm}$ wide. The ambient air entered the collectors at the bottom and solar heated air was drawn from the collector at the top. A circular duct with the diameter of $100 \mathrm{~mm}$ was connected to the outlet of the collector and an axial fan was used to maintain the desired air flow rate through the collector. The cross-section of the collector is shown in Figure 1.

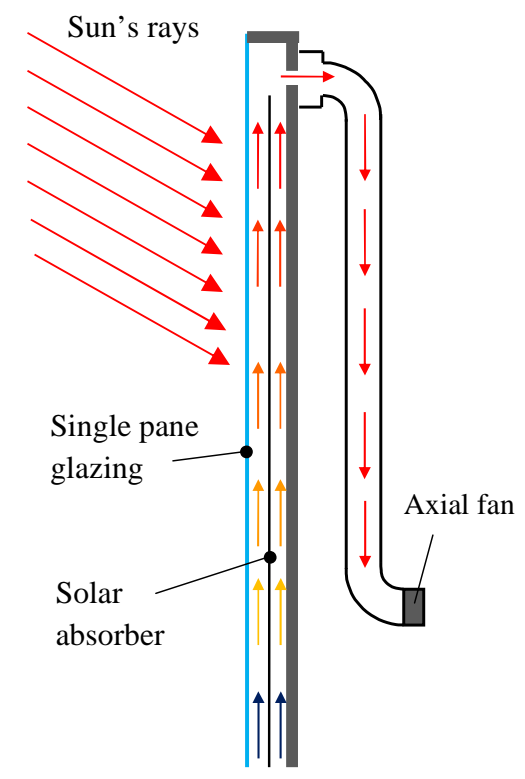

Fig. 1. Front-and-back pass solar collector

One of the collectors had the solar absorber made of sheet metal while the solar absorber of the other collector consisted of aluminium containers filled with paraffinbased phase change material (PCM). The PCMs macrocapsulated in aluminium containers were used in other studies e.g. [8] because the containers can rather easily be integrated with various structures. The dimensions of the containers were $300 \mathrm{~mm} \times 450 \mathrm{~mm} \times 10 \mathrm{~mm}$ and each container accommodated approximately $700 \mathrm{ml}$ of the PCM. The phase change temperature range of the PCM was between $37{ }^{\circ} \mathrm{C}$ and $43{ }^{\circ} \mathrm{C}$. The experimental solar air collectors were not designed for a specific application and the experience with latent heat thermal storage in solar chimneys utilize in the selection of the PCM.

If a solar air collector is used for space heating it usually operates in air circulation mode. It means that the air from inside of a building flows into the collector and the solar heated air returns to the building. In such a case the air temperature at the inlet of the collector does not change much; e.g. for the residential or office buildings it would likely be around $20{ }^{\circ} \mathrm{C}$ during the heating season. On the other hand, if solar air collector is used for heating of ventilation air the air temperature at the inlet of the collector will be the same as outdoor temperature and it will change significantly during the year.

It should also be pointed out in this context that most PCMs have rather wide melting ranges. It means that melting and solidification of a PCM does not take place at one temperature but in a certain (often wide) temperature interval. For that reason it is not easy to obtain enthalpy of fusion of a PCM and some manufacturers rather provide the value of overall thermal capacity in a certain temperature range. The thermal capacity of the PCM used in the containers was $174 \mathrm{~kJ} \mathrm{~kg}^{-1}$ in the temperature range between $35^{\circ} \mathrm{C}$ and $50{ }^{\circ} \mathrm{C}$. The density of the PCM was $880 \mathrm{~kg} \mathrm{~m}^{-3}$ in the solid state and $760 \mathrm{~kg} \mathrm{~m}^{-3}$ in the liquid state.

\subsection{Experimental set-up}

The experiments were performed under real climatic conditions. The collectors were positioned side by side with the same tilt and the same orientation. A photo from the experiment on September 11, 2012, can be seen in figure 2. The collector with the light-weight solar absorber is on the left and the collector with the thermal storage absorber is on the right.

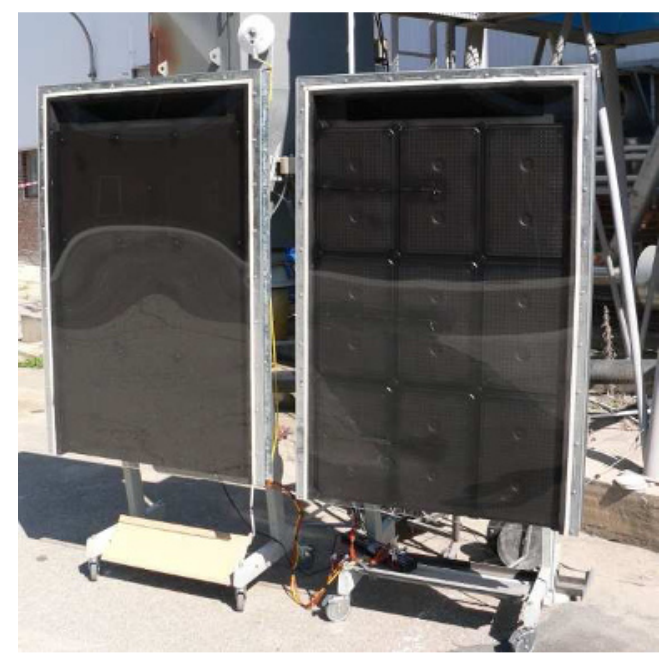

Fig. 2. Experimental solar collectors

The collector mounting frames were equipped with wheels for easier transport and positioning of the collector. The mounting frames allowed positioning of the collectors at any angle between the vertical and the horizontal position. A PC-based data acquisition was used for monitoring of the collectors and the weather conditions. Solar radiation incident on the collectors was 
measured with a pyranometer. Wind speed and direction gauge was installed on a pole above the collectors in order to account for the influence of wind. The T-type thermocouples were used for temperature measurements. The air flow rates through the collectors were obtained by means of the air velocity measurements in the circular duct. The thermo-anemometers were used to obtain the air velocities. All measured values were recorded in 15 second intervals.

\section{Results and discussion}

The experiments took place on the campus of the Brno University of Technology, Brno, Czech Republic, in September 2012. The coordinates of the site were N $49.1^{\circ}$ and $\mathrm{E} 16.5^{\circ}$. The results reported in this paper are for the collectors positioned vertically as would be the case if the collectors were mounted on the building facade.

\subsection{Sunny day performance}

The behaviour of the experimental solar air collectors on a sunny day (September 11, 2012) can be seen in figure 3. The time in all charts in this paper is the Central European Summer Time (CEST). Solar noon at the location was around 1 P.M. CEST. The collectors were oriented to south-west (azimuth $225^{\circ}$ ). The air flow rate through each of the collectors was $105 \mathrm{~m}^{3}$ hour ${ }^{-1}$. Unfortunately, the place where the experiments were carried out was shaded by university buildings in the morning and the afternoon. The astronomical sunset at the location was around 7 P.M. on that day but the sun disappeared behind one of the university buildings just after 3 P.M. Even though the total thermal capacity of the PCM contained in the solar absorber was relatively small (around $0.22 \mathrm{kWh}$ in the temperature interval between $35^{\circ} \mathrm{C}$ and $50{ }^{\circ} \mathrm{C}$ ) there is an observable difference in the outlet air temperatures of the collectors. The air temperature at the outlet of the collector with thermal storage is more stable and less influenced by input temperature fluctuations.

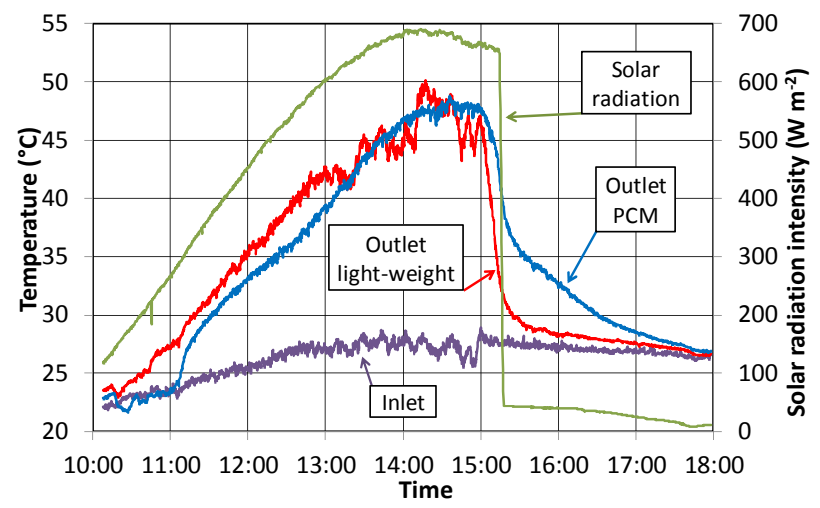

Fig. 3. Outlet air temperatures (Sep. 11, 2012)

The sharp decrease of solar radiation intensity, when the sun disappeared behind the building, makes the effect of thermal storage in the solar absorber even more visible. It took more than an hour to discharge the solar heat accumulated in solar absorber. The thermal outputs of the collectors can be seen in figure 4. Due to the orientation of the collectors to south-west the peak thermal output of the collectors was between 2 P.M and 3 P.M. The total solar radiation incident on the aperture area of each collector $\left(1.35 \mathrm{~m}^{2}\right)$ between 10 A.M. and 6 P.M. was $3.58 \mathrm{kWh}$. The total heat yield of the collectors during that time period was $2.17 \mathrm{kWh}$ for the light-weight collector and $2.23 \mathrm{kWh}$ for the collector with PCM thermal storage. These results indicate slightly higher efficiency of the collector with thermal storage but the difference is so small that it falls within the uncertainty range of the measurements.

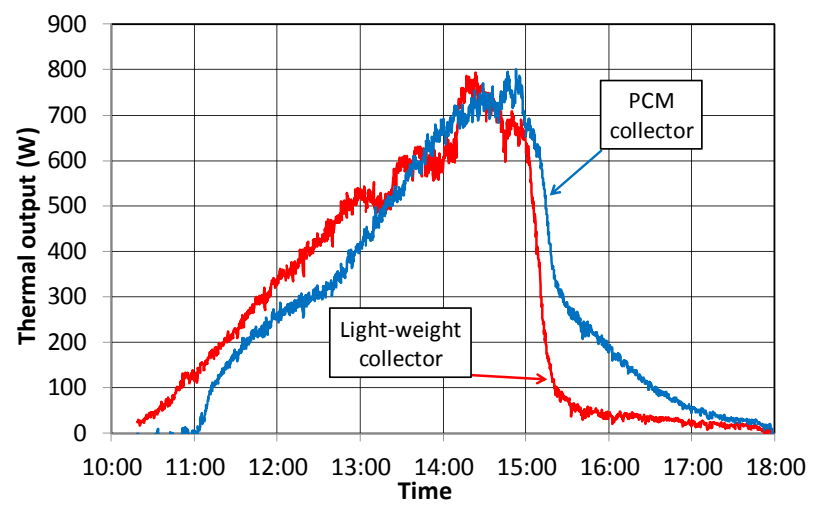

Fig. 4. Thermal output of the collectors (Sep. 11, 2012)

\subsection{Partially-cloudy day performance}

The effect of thermal storage is much more obvious on partially cloudy days. Figure 5 shows temperatures and solar radiation intensity on such a day (September 14).

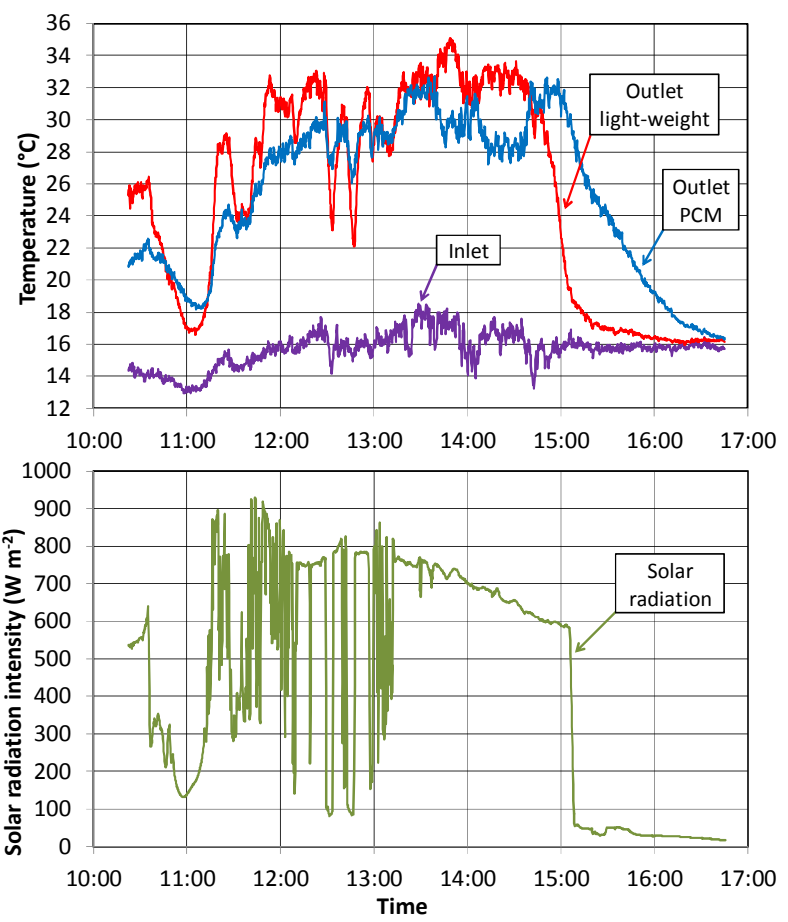

Fig. 5. Outlet air temperatures (Sep. 14, 2012) 
The solar collectors were oriented to due south (azimuth $180^{\circ}$ ). The air flow rate through each of the collectors was $109 \mathrm{~m}^{3}$ hour $^{-1}$ during this experiment. The thermal outputs of the collectors can be seen in figure 6 . The total solar radiation incident on the area of each collector between 10:20 A.M. and 4:45 P.M. was $3.78 \mathrm{kWh}$. The total heat yield of the collector with light-weight absorber was $2.28 \mathrm{kWh}$ and the collector with the absorber containing PCM yielded $2.36 \mathrm{kWh}$ during that time period. The difference between the yields is higher than in case of the sunny day but it is still so small that it falls within the uncertainty range of the measurements.

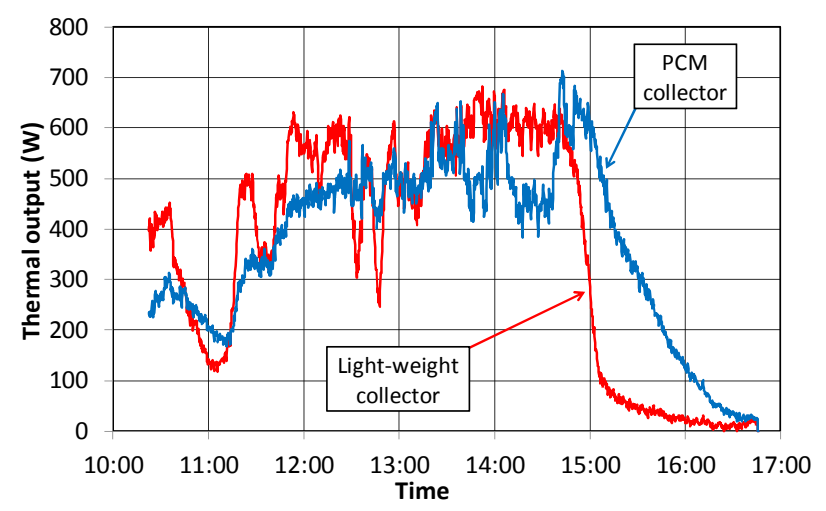

Fig. 6. Thermal output of the collectors (Sep. 14, 2012)

\subsection{Melting of the PCM}

As could be seen in figures 3 to 6 thermal storage influenced the air temperature at the outlet of the collector. The question is whether the PCM partially or fully melted in the described experiments or if it remained in the solid state and functioned only as a sensible heat storage material. Though it was not possible to directly monitor the phase change of the PCM in the containers some assumptions can be made based on the surface temperatures of the containers. The surface temperatures of the middle container in each of 3 rows were monitored. It can be assumed that when the surface temperature on the non-insolated side of the container (the surface facing the non-glazed air cavity) increased above the melting temperature the PCM was fully melted. The container surface temperatures on September 14, 2012, are shown in figure 7.

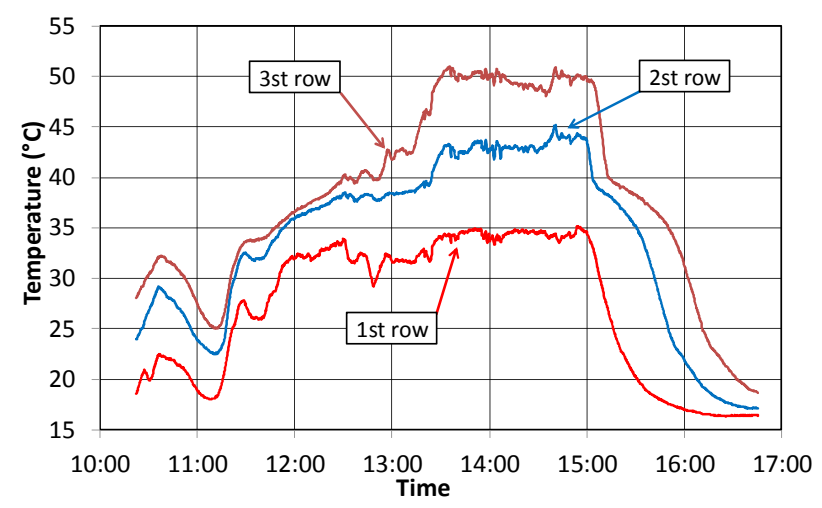

Fig. 7. Temperatures of the non-insolated container surfaces
The first row of the containers was positioned at the bottom of the collector (close to the air inlet) while the third row was at the top. As can be seen in figure 7 the surface temperature in the first row was lower than the melting temperature of the PCM. The surface temperatures in the second and the third row were above the melting temperature of the PCM between 1:30 P.M. and 3:00 P.M. and the phase change (solidification) is clearly visible in the temperature profiles after 3:00 P.M. These findings indicate that it would make sense to use the PCMs with different phase change temperature in each row.

\section{Conclusions}

Thermal behaviour of solar air collector with latent heat thermal storage integrated with the solar absorber was experimentally investigated. The results show that thermal storage contributes to higher stability of the air temperature at the outlet of the collector and also to slightly better overall efficiency of the collector with thermal storage. However, the differences in the heat yield between the collector with light weight absorber and absorber with thermal storage were so small that they fell into the uncertainty range of the measurements. Considering the rather simple design of the collectors the overall efficiency of the collectors that exceeded $60 \%$ in both studied cases was relatively good.

\section{Acknowledgements}

The research leading to the presented results was supported by the Czech Ministry of Education under project OC10051 and the Brno University of Technology standard project No. FSI-S-11-6.

\section{References}

1. R.S. Gill, S. Singh, P. P. Singh, Energy Conversion and Management, 57, 131 (2012)

2. V.V. Tyagia, N.L. Panwarb, N.A. Rahima, R. Kotharic, Renewable and Sustainable Energy Reviews, 16, 2289 (2012)

3. S. V. V. Raman, S. Iniyan, Ranko Goic, Renewable and Sustainable Energy Reviews, 16, 2652 (2012)

4. A. Shukla, D. N. Nkwetta, Y.J. Cho, V. Stevenson, P. Jones, Renewable and Sustainable Energy Reviews, 16, 3975 (2012)

5. H. Benli, Renewable Energy, 50, 58 (2013)

6. M. Dowson, I. Pegg, D. Harrison, Z. Dehouche, Energy and Buildings, 49, 173 (2012)

7. M. M. Alkilani, K. Sopian, M.A. Alghoul, M. Sohif, M.H. Ruslan, Renewable and Sustainable Energy Reviews, 15, 1476 (2011)

8. M. Ostry, D. Beckovsky, 8th IIR Conference on Phase Change Materials and Slurries for Refrigeration and Air Conditioning, Karlsruhe, Germany, pp. 163-169 (2009) 